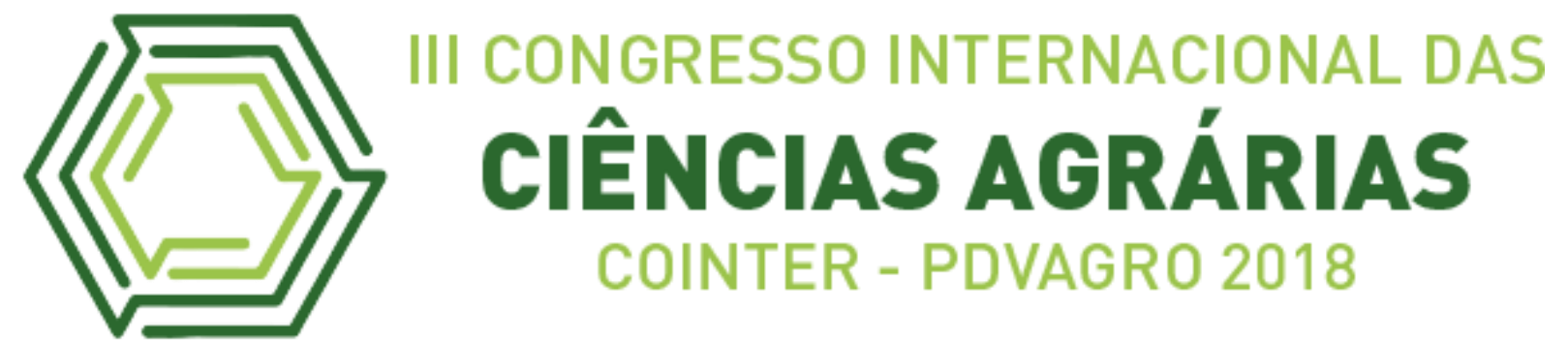

\title{
CULTIVARES DE MILHO EM SISTEMAS DE PLANTIO DIRETO NA PALHA DE LEGUMINOSAS ARBÓREAS EM ALEIAS
}

\section{CORN CULTIVARS IN DIRECT PLANTAIN SYSTEMS ON THE STRAW OF ARUBE LEGUMES IN ALEIAS}

\author{
Apresentação: Pôster \\ José de Arruda Barbosa ${ }^{1}$; Jonathan dos Santos Viana ${ }^{2}$; Thayane Leonel Alves ${ }^{3}$; Luiz \\ Fabiano Palaretti ${ }^{4}$; Emanuel Gomes de Moura ${ }^{5}$

\section{DOI: https://doi.org/10.31692/2526-7701.IIICOINTERPDVAGRO.2018.00409}

\section{Introdução}

Nas regiões de transição para a Amazônia, como a do noroeste do estado do Maranhão, as áreas com a vegetação original já devastada, têm hoje um enorme passivo social representado por um grande contingente de agricultores sobrevivendo abaixo da linha de pobreza, em municípios com os menores IDHs do Brasil, (PNUD, 2000). O cultivo em aléias (Alley cropping) é uma técnica muito útil para melhorar os solos pobres, consistindo no plantio de árvores em fileiras devidamente espaçadas entre si, onde será feito o plantio das culturas agrícolas, no início da estação chuvosa. O principal objetivo desse sistema é a incorporação de matéria orgânica ao solo para o fornecimento de nutrientes as plantas por meio da adubação verde, visto que a adição de matéria orgânica ao solo melhora não somente suas propriedades químicas como também contribuem na agregação das partículas do solo e no estabelecimento de micro-organismo (VASCONCELOS, 2012). Objetivou-se avaliar a produtividade de cultivares de milho em sistemas de plantio direto na palha de leguminosas arbóreas em aleias.

\section{Metodologia}

O experimento foi instalado no Campo experimental do Núcleo Tecnológico de Engenharia Rural do Curso de Agronomia pertencente à Universidade Estadual do Maranhão,

\footnotetext{
${ }^{1}$ Mestrando em Agronomia (Ciência do Solo), UNESP Jaboticabal - SP. E-mail: josearruda777@gmail.com;

${ }^{2}$ Mestrando em Agronomia (Ciência do Solo), UNESP Jaboticabal - SP. E-mail: jonathan santu@hotmail.com;

${ }^{3}$ Mestranda em Agronomia (Ciência do Solo), UNESP Jaboticabal - SP. E-mail: thayaneleonel@hotmail.com;

4 Professor Doutor do Departamento de Engenharia Rural, UNESP Jaboticabal - SP. E-mail: ifpalaretti@fcav.unesp.br;

${ }^{5}$ Professor Doutor do Departamento de Engenharia Rural, UEMA Câmpus São Luís- MA. E-mail: egmoura@hotmail.com;
} 
situado no interior da Ilha de São Luís - MA. As coordenadas geográficas compreendem $2^{\circ} 30^{\prime}$ Latitude Sul e $44^{\circ} 18^{\prime}$ Longitude a Oeste do meridiano de Greenwich. Na região do meio-norte brasileiro, entre a Amazônia úmida e o Nordeste seco. Este local de estudo foi definido visto à disponibilidade de área para plantio e a distância para os laboratórios de análise.

O ensaio foi instalado e conduzido um sistema de cultivo em aléias, com quatro espécies de leguminosas, duas de alta qualidade de resíduos - Leucaena leucocephala (Leucena) e Gliricidia sepium (Gliricídia) e duas espécies de baixa qualidade de resíduos - Clitoria fairchildiana (Sombreiro) e Acacia mangium (Acácia). As espécies de leguminosas foram instaladas no experimento, com espaçamento de 4,0 m entre linhas e 0,5 m entre plantas, organizadas em fileiras mistas e duplas de forma que cada parcela é composta por $20 \mathrm{x} 4$. Foram formados então quatro repetições dos seis tratamentos, para cada cultivar de milho: Tratamento 1: Clitoria + Gliricidia $(C+G)$; Tratamento 2: Acácia + Gliricidia $(A+G)$; Tratamento 3: Leucena + Acácia $(\mathrm{L}+\mathrm{A})$; Tratamento 4: Leucena + Clitoria $(\mathrm{C}+\mathrm{S})$; Tratamento 5: Leucena + Gliricidia $(\mathrm{L}+\mathrm{G})$; Tratamento 6: Testemunha (Test.). O delineamento foi em blocos inteiramente casualizados, totalizando 48 parcelas.

No início do período chuvoso foi semeado entre as fileiras das leguminosas quatro fileiras de milho no espaçamento de 0,9 x $0,3 \mathrm{~m}$. Na oportunidade os galhos das leguminosas foram podados acima de $0,5 \mathrm{~m}$ de altura do solo e a biomassa resultante foi uniformemente distribuída entre as fileiras das diferentes parcelas do mesmo tratamento, onde estão sendo cultivadas as culturas de milho como safra principal. Além disso, foi realizada uma adubação de plantio com $50 \mathrm{~kg} \mathrm{ha}^{-1}$ de $\mathrm{K}_{2} \mathrm{O}$ e $50 \mathrm{~kg} \mathrm{ha}^{-1}$ de $\mathrm{N}$. Mais duas adubações de cobertura com cloreto de potássio e ureia. Cada parcela foi subdivida em duas para o plantio de duas cultivares de milho, sendo a cultivar AG 7088 e uma variedade biofortificado BR 473.

Logo após a semeadura do milho realizou-se o corte das leguminosas a 0,5 $\mathrm{m}$ de altura. As quantidades de biomassa proveniente das leguminosas de semeadura foram: 76,8 $\mathrm{Kg}$ de $\mathrm{N}$ orgânico ha ${ }^{-1}$ (Leucaena leucocephala ; Gliricidia sepium); 57,6 Kg de N orgânico ha-1 (Clitoria fairchildiana; Acacia mangium). Todos os outros tratos culturais e fitossanitários seguiram as recomendações para a cultura do milho. A colheita foi realizada manualmente na maturação fisiológica das culturas aos 140 dias, quando os grãos apresentaram cerca de $25 \%$ de umidade. Na fase da colheita para determinação da produtividade da cultivar AG 7088 e da variedade biofortificado BR 473, foram avaliadas quanto; ao número de plantas por metro, quantidade de espigas por planta, peso das espigas, peso de 100 grãos, frequência de 100 grãos 
e peso total de grãos por hectare.

Os conteúdos de nutrientes do milho foram avaliados em duas etapas: no estágio de pendoamento ou aproximadamente uma semana antes da antese e na fase de maturação fisiológica. Em cada amostragem, três plantas de cada parcela foram selecionadas aleatoriamente e separadas em folhas, caules e (na segunda amostragem) componentes reprodutivos que foram seca a $60^{\circ} \mathrm{C}$ por 3 a 4 dias até peso constante. As concentrações de $\mathrm{N}$ total das plantas de milho foram determinados por digestão método de Kjeldahl (LUTZ, 2005).

Ao final, determinou-se o índice de colheita dos grãos (IC), a remobilização de nutrientes (RN), índice de colheita de nitrogênio (ICN), e a acumulação de nitrogênio póspendoamento (ANPP) calculados utilizando as seguintes fórmulas: $\mathrm{IC}=[\mathrm{MG} /(\mathrm{MG}+\mathrm{MSF}+\mathrm{MSC})] .100 \%$, em que MG: massa de grãos $\left(\mathrm{kg} \mathrm{ha}^{-1}\right), \mathrm{MSF}$ : matéria seca da folha, MSC: matéria seca do colmo. / NR = acúmulo de nutrientes na planta inteira no pendoamento - nutriente em caules e folhas na maturidade. / ICN $=[\mathrm{NG} /(\mathrm{NG}+\mathrm{NC}+\mathrm{NF}) .100 \%$, em que NG: nitrogênio do grão $\left(\mathrm{kg} \mathrm{ha}^{-1}\right), \mathrm{NC}$ : nitrogênio do colmo $\left(\mathrm{kg} \mathrm{ha}^{-1}\right)$, NF: Nitrogênio da folha $\left(\mathrm{kg} \mathrm{ha}^{-1}\right)$. / NA = acumulação de nitrogênio na planta inteira na maturidade - acúmulo de nitrogênio na planta inteira no pendoamento. Os dados foram analisados estatisticamente usando o GraphPad Prism 5 e submetidos à análise de variância e das médias comparadas pelo teste de Tukey a $5 \%$ de probabilidade.

\section{Resultados e Discussões}

Na tabela $n^{\circ} 01$ é possível verificar a eficiência do uso de nitrogênio através da adição de diferentes combinações de biomassas de leguminosas em sistema de cultivo em aleias de duas cultivares de milho.

Tabela 1 - Índice de colheita de Nitrogênio (ICN); Nitrogênio remobilizado (NR) e Nitrogênio acumulado (NA) em duas cultivares de milho em um sistema de combinações de leguminosas, São Luís (MA), 2014.

\begin{tabular}{lccc}
\hline \multicolumn{1}{c}{ TRATAMENTOS } & \multirow{2}{*}{ I. C. N } & N.R & N.A \\
\cline { 3 - 4 } CULTIVAR BR (473) & & \multicolumn{2}{c}{ Kg ha $^{-\mathbf{1}}$} \\
\hline T1 - Clitoria fairchildiana + Leucaena leucocephala & $50,47 \mathrm{ab}$ & $50,56 \mathrm{abc}$ & $66,74 \mathrm{abc}$ \\
\hline T2 - Acacia mangium + Leucaena leucocephala & $48,19 \mathrm{ab}$ & $48,34 \mathrm{abc}$ & $89,12^{\mathrm{a}}$ \\
\hline T3 - Leucaena leucocephala + Gliricidia sepium & $46,58 \mathrm{ab}$ & $8,36 \mathrm{c}$ & $87,43^{\mathrm{a}}$ \\
\hline T4 - Acacia mangium + Gliricidia sepium & $56,87^{\mathrm{a}}$ & $56,52 \mathrm{abc}$ & $97,66^{\mathrm{a}}$ \\
\hline T5 - Clitoria fairchildiana + Gliricidia sepium & $57,22^{\mathrm{a}}$ & $66,00 \mathrm{ab}$ & $82,96 \mathrm{ab}$ \\
\hline T6 - Controle & $44,45 \mathrm{ab}$ & $24,29 \mathrm{bc}$ & $41,28 \mathrm{bc}$ \\
\hline CULTIVAR AG 473 & & & \\
\hline T1 - Clitoria fairchildiana + Leucaena leucocephala & $53,91 \mathrm{ab}$ & $64,52 \mathrm{ab}$ & \\
\hline
\end{tabular}




\begin{tabular}{lccc}
\hline T2 - Acacia mangium + Leucaena leucocephala & $43,52 \mathrm{ab}$ & $39,04 \mathrm{abc}$ & $85,59^{\mathrm{a}}$ \\
\hline T3 - Leucaena leucocephala + Gliricidia sepium & $43,26 \mathrm{ab}$ & $27,95 \mathrm{abc}$ & $85,83^{\mathrm{a}}$ \\
\hline T4 - Acacia mangium + Gliricidia sepium & $51,58 \mathrm{ab}$ & $76,73^{\mathrm{a}}$ & $79,69 \mathrm{ab}$ \\
\hline T5 - Clitoria fairchildiana + Gliricidia sepium & $50,52 \mathrm{ab}$ & $42,80 \mathrm{abc}$ & $97,42^{\mathrm{a}}$ \\
\hline \multirow{2}{*}{ T6 - Controle } & $26,12 \mathrm{~b}$ & $18,24 \mathrm{abc}$ & $28,86 \mathrm{c}$ \\
\hline CV $(\%)$ & 24,83 & 46,79 & 22,23 \\
\hline
\end{tabular}

* Médias seguidas das mesmas letras nas colunas, não diferem estatisticamente entre si pelo teste de Tukey a $5 \%$.

De acordo com Moura et.al. (2012) as quantidades de nutrientes presentes nos ramos de leguminosas arbóreas no sistema de cultivo em aleias variam em função de diferentes fatores nos quais podem ser destacados: espécie da leguminosa, tipo de solo, intensidade do corte dos ramos e adubações. Os ramos quando adicionados ao solo são os que apresentam um grande potencial para o fornecimento de nutrientes, em especial nitrogênio e potássio.

Contudo, foi possível verificar que os resultados demonstrados diferem dos resultados encontrados em um trabalho desenvolvido por MOURA et.al. (2012) que analisaram a eficiência do uso de nitrogênio e potássio no mesmo agroecossitema, onde a combinação de Leucaena leucocephala e Acacia mangium demonstrou os resultados mais significativos para os mesmos parâmetros. A relação $\mathrm{C} / \mathrm{N}$ determina o processo de decomposição, mineralização e disponibilidade de nitrogênio $(\mathrm{N})$ para as plantas. Ela não é constante em todo o processo de desenvolvimento das culturas, mas varia com a idade das plantas (BRAGA, 2009). Isso se deve a baixa relação carbono/ nitrogênio existente nessas duas leguminosas arbóreas, fazendo com que a liberação e a ciclagem de nutrientes nessa combinação seja mais rápida do que as demais combinações utilizadas.

$\mathrm{Na}$ figura $\mathrm{n}^{\mathrm{o}} 01$, verifica-se os valores encontrados para o parâmetro produtividade das duas cultivares de milho analisadas (BR 473 e AG 7088).
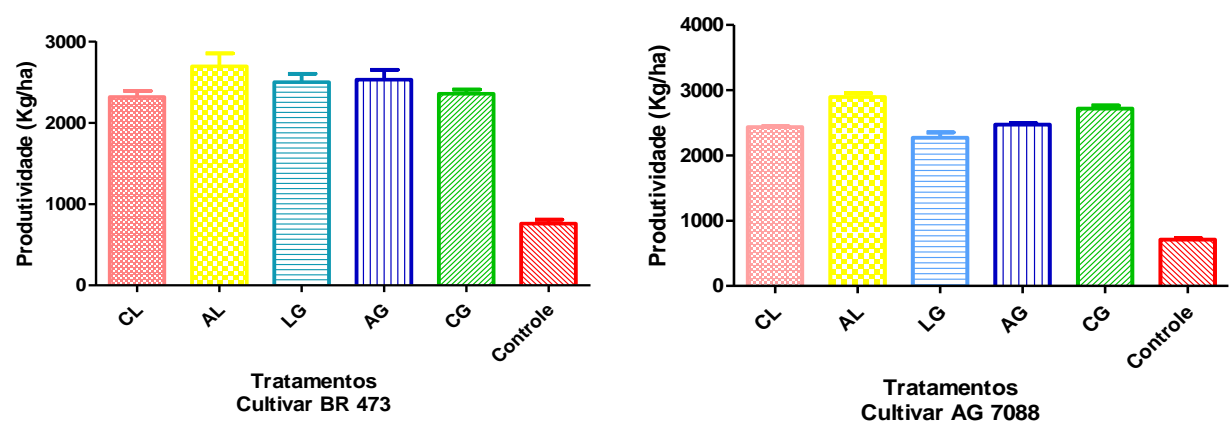

Figura 01. Produtividades de duas cultivares de milho em sistema de aleias com diferentes combinações de leguminosas, São Luís - MA.

* Tratamentos: CL (Clitoria fairchildiana + Leucaena leucocephala); AL (Acacia mangium + Leucaena leucocephala); LG (Leucaena leucocephala + Gliricidia sepium); AG (Acacia mangium + Gliricidia sepium); CG (Clitoria fairchildiana + 
Gliricidia sepium).

** Valores significativos pelo Teste de Tukey a 5\%.

Em relação à produtividade das duas cultivares de milho percebeu-se diferenças significativas entre os tratamentos com combinações de leguminosas [BR 473(P <0,05; $\mathrm{F}=50,76 ; \mathrm{R}=0,9338) ; \mathrm{AG} 7088(\mathrm{P}<0,05 ; \mathrm{F}=276,1 ; \mathrm{R}=0,9871)]$. Em ambas cultivares de milho a combinação de Acacia mangium e Leucaena leucocephala demonstrou resultados superiores aos demais tratamentos (Figura 1).

Os dados de produtividade da cultivar QPM (BR 473) possui variação semelhante aos valores encontrados por Aguiar e Moura (2003) estudando o mesmo sistema de aleias e por Souza (2003) em um sistema de aleias com combinações das leguminosas acácia, gliricídia e sombreiro em um agroecossistema no Maranhão. Contudo, os valores ainda estão abaixo dos valores médios indicados para a cultivar no sistema convencional. Mas levando-se em consideração a prática da famosa agricultura itinerante utilizada ainda no Maranhão, observase nessas combinações de leguminosas neste sistema de cultivo, boas representatividades da melhor eficiência do nitrogênio e uma melhor resposta em termos de produtividade quando comparado ao plantio em áreas limpas utilizando-se o fogo e cinzas como adubo.

Já para a cultivar AG 7088 os valores de produtividade encontrados estão abaixo dos valores estipulados por Gontijo et al., (2013). Contudo, os valores ainda são considerados expressivos quando comparados os sistemas de cultivos da cultura do milho pelo sistema convencional de corte e queima no Maranhão.

\section{Conclusões}

O plantio direto na palha de leguminosas é uma estratégia capaz de aumentar a produtividade em solos de baixa fertilidade natural no Maranhão. As combinações de biomassas são capazes de atender parte das demandas do milho por $\mathrm{N}$ e $\mathrm{K}$, o que pode incrementar a produtividade, reduzir a necessidade de fertilizantes minerais nitrogenados e potássicos e facilitar a construção de agroecossistemas de baixo input. Porém, a fertilização mineral é fundamental para que o cultivar atinja todo o seu potencial produtivo, pois os solos do trópico úmido apresentam baixa disponibilidade de nutrientes e o sistema de aleias não é capaz de manter os níveis de $\mathrm{P}, \mathrm{K}, \mathrm{Ca}$ e Mg em níveis adequados no solo.

O tratamento Acacia mangium e Leucaena leucocephala foi superior aos demais, ao se considerar todos os parâmetros analisados, e pode ser recomendado para aumentar a produtividade e o peso dos grãos em plantio direto nas condições edafoclimáticas do trópico 
úmido. Além disso, a variedade QPM mostrou-se adequada para o cultivo em sistemas de aleias no trópico úmido maranhense, apresentando bons resultados para eficiência do uso de $\mathrm{N}$ e também produtividade, além de que o mesmo supri consideravelmente as necessidades humanas de vitamina A.

\section{Referências}

AGUIAR, A. das C. F; MOURA, E. G. Crescimento e produtividade de duas cultivares de milhode alta qualidade protéica em solo de baixa fertilidade. Bragantia, Campinas, v.62, n.3, p.429-435, 2003.

BRAGA, Gastão Ney Monte. Na sala com Gismont assuntos sobre agronomia: A relação C/N. 2009. Disponível em:< http://agronomiacomgismonti.blogspot.com.br/2009/06/relacaocn.html>. Acesso em 27 de Julho de 2018.

EMPRESA BRASILEIRA DE PESQUISA AGROPECUÁRIA - EMBRAPA. Serviço Nacional de Levantamento e Conservação de Solos. Sistema Brasileiro de Classificação de Solos. Rio de Janeiro, 1999. 412p.

GONTIJO NETO, M. M.; MAY, A.; VANIN, A.; SILVA, A. F. da.; SIMÃO, E. de P.; SANTOS, E.A. dos.; QUEIROZ, L. R.; BARCELOS, V. G. F. Avaliação de cultivares e épocas de semeadura de milho safrinha na região de rio verde (GO). In: Anais...XII Seminário Nacional de Milho safrinha, Dourados, 6p. 2013.

LUTZ, A. Métodos físico-quimicos de análises de alimentos. 2005. Disponível em: <http://www.ial.sp.gov.br/>. Acesso em: 25 de Julho de 2018.

MOURA, E. G.; OLIVEIRA, A. K. C.; COUTINHO, G. ; PINHEIRO, K. M. ; AGUIAR, A. C. F.. Management of a cohesive tropical soil to enhance rootability and increase the efficiency of nitrogen and potassium use. Soil Use and Management, v.28, p.370-377, 2012.

PNUD. Relatório de Desenvolvimento Humano 2000. 2000. Disponível em: <http://www.pnud.org.br>. Acesso em 27 de Julho de 2018.

SOUZA, E.A. de. Plantio direto na palha de leguminosas como estratégia para melhorar a eficiência de uso de nutrientes em milho QPM. Dissertação de Mestrado (Programa de PósGradução de Agroecologia), UEMA, São Luis, 66p. 2013.

VASCONCELOS, Maria da C. da C. de A. Cultivo em aleias: uma alternativa para pequenos agricultores. Revista ACSA. v. 8, n. 3, p. 18-21, jul - set, 2012. 